\title{
1. Analytical jurisprudence and its discontents
}

As I noted in the Introduction, the legal theories of Hart, Raz and others are often understood as exercises in the application of the philosophical method of conceptual analysis to law, in which identification of necessary and essential features of law is taken to be the goal. Yet this conception of the aim and method of analytical jurisprudence has come under such sustained attack in legal theory that its possibility and value can no longer be taken for granted, but must be investigated. The challenges to analytical jurisprudence tend to come in a variety of forms, but these can be distilled into three prominent categories: first, there are those who suppose that engagement in conceptual analysis cannot resolve boundary disputes about the concept of law, which was the very purpose of conceptual analysis in the first place. Second, there are those who argue that conceptual analysis, as a general philosophical method, relies on a deeply flawed epistemology which has for a long time now been discredited. And third, there are those who argue that the sheer diversity of types of law renders the pursuit of a single, overarching concept of law pointless. In this chapter I will present each of these categories of challenges in turn, and in the next chapter I will measure their net impact on the project of analytical jurisprudence.

\section{CONCEPTUAL ANALYSIS IN ANALYTIC PHILOSOPHY}

Before introducing the three challenges to analytical jurisprudence's reliance on conceptual analysis, it is important to lay out, for present and later purposes, the precise picture of conceptual analysis which is under attack both within legal theory and philosophy more generally. This will in turn help to show, in subsequent chapters, that while analytical jurisprudence and conceptual analysis of law have often been identified as one and the same project, as interchangeable descriptions of the same enterprise, the identification is a false one. While some degree of conceptual analysis is part of analytical jurisprudence, it is certainly not the most important 
part, let alone the whole of the project of analytical jurisprudence. At least, this is what I shall attempt to show.

On a familiar view, conceptual analysis is simply reflection on the application of familiar concepts or categories to particular cases by appeal to intuitions, until something like necessary and sufficient conditions for the application of those concepts or categories emerge. ${ }^{1}$ So, for example, analysis of the concept of chair or knowledge is completed once we have reflected on a representative range of possible and imaginary examples of things that could be chairs or knowledge to see where our intuitions lie. Two contemporary advocates of conceptual analysis further explain that the reflective exercise involved in conceptual analysis is essentially to make explicit what is already implicit in our ordinary understanding and use of particular concepts. For example, in discussing the concept of belief Frank Jackson writes that ' $[\mathrm{t}]$ he role of the intuitions about possible cases so distinctive of conceptual analysis is precisely to make explicit our implicit folk theory and, in particular, to make explicit which properties are really central to some state's being correctly described as a belief.'2 More recently Colin McGinn explains:

Knowledge of a conceptual analysis, in the explicit sense, is thus knowledge of knowledge, arrived at by reference only to the knowledge inherent in possessing the concept. We come to know (in one way) what we already know (in another way), guided only by what we know in knowing the concept being analysed. Conceptual analysis is thus coming to have explicit knowledge of what we already know implicitly, guided by what we know implicitly. It is the attempt to arrive at knowledge of knowledge driven by knowledge. ${ }^{3}$

Such accounts of conceptual analysis give philosophy a determinate goal, to make explicit our implicit knowledge of particular objects, such as knowledge, belief or chair, and a relatively simple method of taking aim at that goal, investigation of our shared intuitions and common knowledge (typically manifested, as we will see, in our shared linguistic expressions).

The views of McGinn and Jackson, that conceptual analysis is the exercise of making explicit what is already implicit in our ordinary, unassailable views of some subject-matter, of course have their roots in the works

1 For example, for some classic analyses of the concept of knowledge, see A.J. Ayer (1956); R.M. Chisholm (1957); and E. Gettier (1963). For recent work on the role of intuitions in philosophy, see M.R. Depaul and W. Ramsey, eds (1998); and H. Cappelen (2012).

$\begin{array}{ll}2 & \text { F. Jackson (1998) } 38 . \\ 3 & \text { C. McGinn (2012) } 68 .\end{array}$ 
of early analytic philosophers such as G.E. Moore and Bertrand Russell. ${ }^{4}$ For example, a key feature of Moore's approach to philosophy, which became characteristic of much analytic philosophy to follow, was the centrality attributed to common sense beliefs. For Moore, philosophical analysis of knowledge, for example, must ultimately be tested against prephilosophical, common sense convictions. Scott Soames nicely explains Moore's commitment in this respect:

As Moore saw it, conflicts between speculative philosophical principles and the most basic convictions of common sense confront one with a choice. In any such case, one must give up either one's common sense convictions, or the speculative philosophical principle. Of course, one ought to give up whichever one has the least confidence in. But how, Moore wondered, could anyone have more confidence in the truth of a general philosophical principle than one has in the truth of one's most fundamental common sense convictions - convictions such as one's belief that there are many different objects, and many different people, that exist independently of oneself? In the end, Moore came to think that one's confidence in a general principle of philosophy never could outweigh one's confidence in convictions such as these. In other words, Moore came to think that philosophers have no special knowledge that is prior to, and more secure than, the strongest examples of what we all pre-theoretically take to be instances of ordinary knowledge. As a result philosophers have nothing that could be used to undermine the most central and fundamental parts of what we take ourselves to know. ${ }^{5}$

As Soames goes on to explain, Moore's commitment to common sense convictions gives rise to a distinct job for philosophy:

According to [Moore], the job of philosophy is not to prove or refute the most basic propositions that we all commonly take ourselves to know. We have no choice but to accept that we know these propositions. However, it is a central task of philosophy to explain how we do know them. And the key to doing this, Moore thought, was to analyse precisely what it is that we know when we know these propositions to be true. ${ }^{6}$

Subsequent developments in analytic philosophy would build on the role Moore recognized for pre-theoretical, common sense beliefs. In the ordinary language philosophy and logical positivism of A.J. Ayer, for example, only propositions whose truth could be verified against facts in the world were thought to have meaning. This led Ayer and others to be quite sceptical of metaphysical claims and claims about morality, as neither of

4 In what follows I am drawing primarily on the excellent critical survey provided in S. Soames (2003a).

5 Soames (2003a) 9.

6 Soames (2003a) 9. [original boldface] 
these, Ayer thought, could be verified. This did not mean, however, that Ayer and other ordinary language philosophers and logical positivists did not recognize other kinds of statements beyond those that could be verified (and so were meaningful) and those that could not be verified (and so were meaningless). A third kind of proposition Ayer and others identified were analytic propositions, such as ' $2+2=4$ ' or 'a bachelor is an unmarried man'. Such propositions were not about the world, and so could not be verified, but they still had meaning and truth. Their meaning was internal, in the sense that it is part of the very meaning of ' $2+2$ ' that it equals ' 4 ', and it is the very meaning of 'bachelor' to be 'an unmarried man'. So according to Ayer, these propositions are not only analytic (they are true simply in virtue of their meaning), but they are also necessarily true: it could not be otherwise that ' $2+2=4$ ' and that 'a bachelor is an unmarried man' without changing the meanings of the terms. Further, because analytic propositions say nothing about the world, and could not be verified or disconfirmed by empirical methods or observation, they were also thought to be a priori truths: they are known, and are known to be true, without any need for empirical evidence to confirm them (though of course some initial experience is required to learn what the terms mean).

This brings us to a second key feature of early analytic philosophy. As Soames explains, Ayer and Wittgenstein, for example, and numerous others, treated analyticity, necessity, and apriocity as one and the same:

Wittgenstein and the positivists held that all necessary truths are analytic, and that meaning was the source of necessity. For Wittgenstein, the basis of this view lay in his contention that for a sentence to say anything, for it to provide any information, is for its truth to exclude certain possible states that the world could be in. Since necessary truths exclude nothing, they say nothing; and since they say nothing about the way the world is, the way the world is makes no contribution to their being true. Hence, their truth must be due to their meaning alone. The positivists, who found this conclusion welcome, emphasized a different line of reasoning. Being empiricists, they believed that all knowledge about the world is dependent on observation and sense experience. It follows that since a priori truths can be known independently of observation and sense experience, they must not be about the world; and if they don't tell us anything about the world, then the world must play no role in determining that they are true. Rather, their truth must be due to their meanings alone. ${ }^{7}$

Soames concludes:

If one thinks about these motivations, one sees that, in effect, Wittgenstein's reasoning identified the necessary with the analytic, whereas the positivists'

7 Soames (2003a) 261. [original boldface] 
reasoning identified the apriori with the analytic. Although in theory these certainly could have amounted to different identifications, in practice they didn't. There was no real disagreement between Wittgenstein and the positivists on this point, because both identified the necessary with the apriori. Thus, for these philosophers, the necessary, the apriori, and the analytic were one and the same. ${ }^{8}$

Identification and explanation of analytic truths was of course also meant to mark a distinction from synthetic truths, which were about the world and so could be otherwise. Synthetic truths were therefore thought to be contingent and also known a posteriori. ${ }^{9}$ The analytic-synthetic distinction occupied a central place in analytic philosophy for a long time, and in particular helped to define the task of analytic philosophy: analytic philosophy was to be concerned with explanation of the nature of analytic truth and identification of particular necessary truths about knowledge, beliefs, intentions, the mind, and a whole host of other concepts.

This is of course only a very brief, incomplete and selective account of early analytic philosophy, covering only roughly the first half of the twentieth century. Many philosophers, and numerous variations on the themes identified above have not been mentioned. But I do not think the account is objectionably brief, incomplete and selective, since it helps to situate the views of Jackson and McGinn with which we began, who are two recent advocates of the method of conceptual analysis. On their views, which we can now see have clear affinities with early analytic philosophy, knowledge and truth can in fact be arrived at by means of conceptual analysis, whereby analysis of the use and understanding of particular concepts can yield analytic and so necessary truths about those concepts.

I have also not introduced many of the influential criticisms of early analytic philosophy, particularly the criticisms of W.V.O. Quine and Saul Kripke, and how Jackson and McGinn respond to these. This is not, however, my present aim, nor is it necessary for the purposes of this chapter. While I shall return to Quine later in this chapter when presenting Brian Leiter's naturalist objection to analytical legal theory, and I shall present some of Kripke's ideas in Chapter 4 (in particular, his identification of necessary a posteriori truths), it is important to turn now to the objections to analytical legal theory, which all center on the purported use, and failure, of conceptual analysis of law to solve any of the problems analytical legal theory was intended to solve.

8 Soames (2003a) 261-2. [author's notes omitted]

9 Though of course other possible combinations were identified and emphasized by other, sometimes earlier philosophers. Kant, famously, insisted on the necessity of synthetic a priori truths. See I. Kant (1965). 
It is important to note at the outset a common theme running through the various objections we will now consider. All of them, as we will see, tend to focus on the following presumption of conceptual analysis in legal theory: that there is a single, unified and coherent concept of law out there, whose properties are not contradictory but simply waiting to be made explicit. In other words, the presumption is that there is consistency and agreement in our pre-theoretical, common sense convictions about instances of law. Such critics might grant the presumption, for the sake of argument, that there are single, unified abstract objects such as the concept of 'bachelor' or '=', and maybe even for 'knowledge', 'chair' and 'belief' as well, for which we only need to make explicit what we already know implicitly in the mere possession of such concepts. But in the case of law, such a presumption is far from safe. As the critics of conceptual analysis of law argue, we cannot simply assume what must be demonstrated.

\section{SELF-UNDERSTANDING AND IRRESOLVABLE BOUNDARY DISPUTES}

The first sceptical challenge to conceptual analysis in analytical jurisprudence begins with observation of longstanding disagreements about what the true concept of law is. Through various types of argument it attempts to demonstrate that the disagreements are in fact irresolvable. The conclusion typically reached is that legal theorists are therefore better off abandoning the exercise of attempting to establish the truth or correctness of any particular explanation of the concept of law. Two theorists who have recently raised this particular objection are Dan Priel and Liam Murphy. ${ }^{10}$ It will be useful to begin with their arguments.

On the dominant understanding of analytical jurisprudence its task is to offer a theory of law which identifies and explains the necessary and essential features of law, and helps people to understand how they understand themselves through analysis of their shared concept of law. This view of the task of analytical jurisprudence is best associated with Joseph Raz, who puts the two beliefs together as follows: 'legal theory attempts to capture the essential features of law, as encapsulated in the selfunderstanding of a culture. ${ }^{11}$ Such a view might seem unobjectionable,

10 It is important to note that an earlier version of this objection can be found in R. Dworkin (1986) where he discusses 'theoretical disagreements'. See also B. Leiter (2011).

11 J. Raz (2009a) 98. 
but upon reflection Priel contends that pursuit of essential or necessary features is in fact incompatible with the attempt to explain a particular culture's self-understanding.

There are several steps in the argument Priel uses to generate the incompatibility. First, he argues that if knowledge of necessary features of law is the objective, a certain kind of empirical investigation is ruled out as a possible means to attaining such knowledge. Commenting on the distinction between sociology of law and philosophy of law, Priel writes:

Amassing all instances of laws and trying to find what they have in common is exactly the kind of empirical, sociological inquiry that legal philosophy is to be distinguished from. What philosophy of law calls for . . . is an inquiry into what something must be in order to be law, what are the features that if something does not exhibit, it ipso facto will no longer count as law. Such an inquiry cannot be based on an empirical investigation of examples of laws, no matter how many we examine; it must be based on a conceptual, a priori inquiry. ${ }^{12}$

However, and this is the second step in Priel's argument, the kind of conceptual, a priori inquiry required is not of the regular kind in which we try to gain knowledge by looking for propositions which are necessarily true in virtue of the very meaning of the terms of the propositions and logical relations they employ. Priel explains:

Suppose we believe conceptual analysis is a philosophically respectable method of inquiry, how should it be conducted when trying to explain the nature of law? Would it mean that a theorist could simply come to see the boundaries of the concept of law, or the necessary features of law, in the abstract? Could the theorist argue from this that whatever does not fit the account provided is simply not law? This does not seem right, and it does not seem right because unlike in the more familiar cases of (purported) a priori knowledge (such as the claim that nothing can be red and green all over at the same time, or that 2 and 2 are 4), we are not trying to learn what the world is like by trying to see what we find inconceivable, in the case of law we use this method to understand what a contingent and highly varied social phenomena is. ${ }^{13}$

So conceptual analysis in the philosophy of law requires at least some familiarity with law in the world, which provides the data upon which to theorize. Such data also provides the means by which to test competing theories of law:

Hart, Raz, and other legal philosophers routinely examined their own and other philosophers' competing accounts of the nature of law against factual

\footnotetext{
12 D. Priel (2007) 175-6.

13 Priel (2007) 176.
} 
counter-examples of instances of law; and they (as Hart famously did with regard to Austin's account) judged other theories as false because they failed to pick out instances of law or because they ended up covering by their accounts things that are not law. ${ }^{14}$

Priel draws the following conclusion: conceptual analysis does not in fact, and cannot, proceed via any kind of a priori, logical exercise aimed at discovering necessary or essential features of law. Instead, "the "direction" of jurisprudential inquiry is from some samples of law (i.e., pre-theoretically agreed upon examples of things that are law), to a theory that tries to show what the necessary and important features these samples (together with all other laws) have'. ${ }^{15}$

Everything would seem to hang, then, on what counts, pre-theoretically, as law. ${ }^{16}$ It is here, however, where the hopes for conceptual analysis, and identification of law's necessary features, come to an end. The third step of Priel's argument is meant to show that conceptual analysis has no means to resolve disputes about what counts as law in the first place, at a pre-theoretical level. He offers the following thought experiment. Suppose we compare the views about legal validity of two different societies. The self-understanding of the first society is that 'something is law only if it is moral, and that public officials' actions can be legitimate only if they act on laws that do not contradict certain moral principles, which they consider to be part of the law.' ${ }^{17}$ Suppose also that they believe that certain members of the society are able to identify the true requirements of morality. In the second society, since people hold different beliefs about morality and government, a self-understanding forms which maintains that conformity with moral principles does not count among the conditions of legal validity. Priel formulates the issue of the comparison as follows:

The question now is whether, given their attitudes about particular laws, if members of the two societies had been asked to consider things in the world and distinguish between laws and non-laws they would have given the same answer. I believe it is clear that the answer is no: if members of one society had been presented with laws of the other society and had been asked whether they are laws, they would have given a different answer from the one given by members of the other society. At the very least they would have said: 'these are laws only if we adopt the others' view on this question'. ${ }^{18}$

\footnotetext{
Priel (2007) 177.

Priel (2007) 187.

See also B. Tamanaha (2011) 295-6.

Priel (2007) 179.

Priel (2007) 179-80.
} 
As Priel contends, there is no way of resolving the disagreement between the two societies and their views about law, and the reason is simple. If it is part of the task of conceptual analysis to explicate the self-understanding of a particular community's view of law, in other words, to explain its concept of law, then if two societies or cultures have different views or concepts of law, which leads them to treat different things as law, at a pre-theoretical or at least pre-reflective level, the best conceptual analysis can do is report that there are multiple, and conflicting concepts of law. This in turn means that any purported necessary or essential features of law are not really necessary or essential features of law at all, but only necessary or essential features of particular, culturally or socially relative self-understandings. ${ }^{19}$

There are two general conclusions Priel draws from his analysis, one negative and one positive. The negative conclusion: analytical jurisprudence is incapable, given its misguided reliance on pre-theoretical agreement on examples of law, of reaching necessary or essential truths. ${ }^{20}$ Second, and more positively, there is plenty of room for analysis of particular phenomena which pose puzzles in their understanding. Here is how Priel describes the alternative approach for legal theory:

All one needs to be able to do is identify a puzzle, which may be a 'philosophical' question that may be relevant only to understanding a particular legal system, or part of a legal system, which can be much more easily identified and individuated than law in general or even just our concept of law. Moreover, in offering an answer to the puzzle the theorist need not presuppose that the account can explain equally well, say, English law, Soviet law, Roman law, and Islamic law. So long as one succeeds in solving a puzzle about, say, English law, one has given us something of value. ${ }^{21}$

Such an approach, Priel believes, can make use of inductive generalization about non-necessary features of law, but more importantly, it will free legal theorists from the impossible and misguided task of discovering necessary or essential features of law. We might even say that on Priel's view legal theorists are indeed better off not asking about the nature of law at all.

Liam Murphy also believes that conceptual debates in analytical jurisprudence are fundamentally unsolvable as debates about what law really is. Murphy writes:

Both Raz and Dworkin propose ways of finding the true content of the concept of law underneath what they must regard as the superficial equivocation in the 
concept as it is actually employed. This seems to me to be a hopeless project. When it comes to the boundary of law and morality, there is no truth of the matter. There are just different ways of drawing that boundary, preferred by different people. ${ }^{22}$

Like Priel, Murphy believes that the problem lies precisely in the absence of agreement, in participants' understanding, on what counts as law. As he says, '... there is insufficient agreement in the intuitions that are the data for any philosophical conceptual analysis ${ }^{23}$, and '[i]t is hard to see how conceptual analysis can settle a disagreement that is present in the very data that the analysis is supposed to explain. ${ }^{24}$ One might conclude from this claim that Murphy - like Priel - must think that disputes about the boundary between law and morality are best abandoned, since there is no hope of resolution. This is not Murphy's view. In a return to an argument Hart made in some of his early work (following Jeremy Bentham) about the practical effects of different attitudes to law, Murphy proposes that different concepts or theories of law are best judged not according to their truth (since there is no truth), but instead according to their practical political consequences: 'the methodology I favour for thinking about the boundary of law is what would be called a practical political one: the best place to locate the boundary of law is where it will have the best effect on our self-understanding as a society, on our political culture'. ${ }^{25}$ When judged against this standard, Murphy argues that it becomes possible to decide between competing theories of law. ${ }^{26}$ If quietism - an unwillingness to question or indifference towards the morality or wisdom or justice of the state's norms - is the greatest danger for a citizenry, then it follows, according to Murphy, that we are all better off on practical political grounds if we adopt a positivist concept of law. The belief that nothing follows about what should be done, all things considered, from the mere existence of law will foster and encourage the kind of vigilance citizens need.

The views of Priel and Murphy, if sound, strike at the core of conceptual analysis as a method of identifying law's necessary and essential features, in that they show why it might simply be impossible to apply the general philosophical method of conceptual analysis to law. Conceptual analysis of law, to get off the ground, must presume that there is a single, coherent, and unified concept of law which underlies the various intuitions and uses

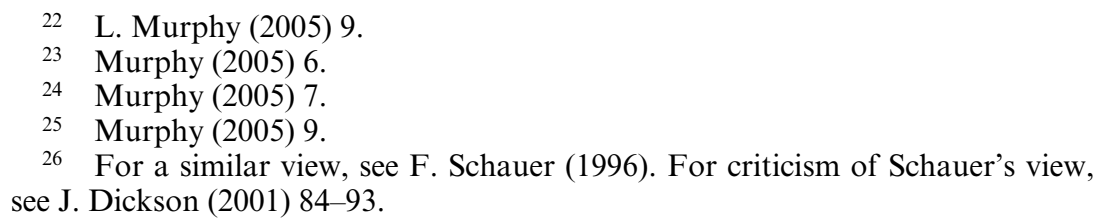


theorists draw on in elucidating the nature of law. But if these intuitions and uses do not in fact settle on any such concept, then conceptual analysis would seem to fail at a foundational level.

\section{NATURALIZED JURISPRUDENCE}

The second challenge to conceptual analysis in legal theory is closely related to the boundary objection but is perhaps more familiar, as it draws on a more general challenge to conceptual analysis in philosophy which I mentioned earlier. This is the naturalistic challenge best associated with the arguments of W.V.O. Quine, who argued that there are no a priori or analytical truths, since there is no sound distinction between analytic and synthetic truths and all propositions are in principle revisable when tested against empirical observation and assessed in light of other beliefs. ${ }^{27}$ In Quine's view, we should only rely on conceptual claims which figure among or are continuous with the best scientific explanations of the world. There simply are not any truths to be had in philosophy beyond those that work with science, and there is no other way to test philosophical or conceptual claims except by investigating their adoption and service in the best scientific theories.

In a series of articles culminating in his book, Naturalizing Jurisprudence, ${ }^{28}$ Brian Leiter has put the lessons of Quine's arguments in epistemology to work in legal theory. According to Leiter, legal theorists ought to accept as established (a) Quine's view that there are no genuine analytic or necessary truths, and (b) that a priori appeals to intuitions will at best reveal contingent and local beliefs. In Leiter's view, '[t]he real worry about jurisprudence is not that it is descriptive - of course it is (or tries to be) - but rather that it relies on two central argumentative devices - analyses of concepts and appeals to intuition - that are epistemologically bankrupt. ${ }^{29}$

In Leiter's view, (a) and (b) should be enough to convince legal theorists that conceptual claims about law, which appeal as they do to 'our intuitions', are only defensible to the extent to which they are continuous with the methods and results of social scientific accounts of law. Leiter advocates a significant change to the methodology of jurisprudence, arguing that conceptual analysis must be replaced in large part by "naturalized

27 See, e.g., W.V.O. Quine (2004).

28 B. Leiter (2007).

29 Leiter (2007) 175. 
jurisprudence', drawing as it does on contemporary developments in epistemology and the philosophy of science. ${ }^{30}$ The replacement, however, will not be complete, since as even Leiter acknowledges, some concept of law will be needed to group together sources of law and legal phenomena to be studied naturalistically. ${ }^{31}$ This is an important observation, and one well worth bearing in mind to ward off the thought that Leiter is suggesting that a naturalistic approach will completely eliminate any need for conceptual theories of law.

Leiter provides a helpful illustration to show how naturalized jurisprudence picks out some concepts of law as superior to others, without appeal to intuitions or some other pseudo-empirical method. His illustration involves a comparison between two models which purport to predict the outcomes of judicial decision-making. On the 'Attitudinal Model', developed by American legal realists Jeffrey Segal and Harold Spaeth, the best means to predict the decisions of judges is to look at the combination of the facts of a case and the 'ideological attitudes and values' of the judges. ${ }^{32}$ An alternative to the Attitudinal Model is the 'Legal Model', according to which '. . . it is valid sources of law, in conjunction with valid interpretive methods applied to those sources, that determine outcomes .... ${ }^{33}$ As Leiter reports, the Attitudinal Model, when tested, is relatively successful:

Looking at more than thirty years of search-and-seizure decisions, Segal and Spaeth found that the Attitudinal Model correctly predicted $71 \%$ of the votes by justices: that is, the ideological attitudes of the judge towards the underlying factual situations (and their variations) explained the vote of the judge nearly three-quarters of the time. ${ }^{34}$

The Legal Model, on the other hand, suffers from a major flaw which compromises its ability to predict judicial decisions at all: it fails to appreciate the legal realist lesson that law is fundamentally indeterminate, and so provides no unique guidance to judges, always leaving them free to decide one way or another. Here Leiter quotes directly from Segal and Spaeth:

30 It is worth noting, however, that Leiter does not spend much time exploring other recent contributions in epistemology and metaphysics, nor does he consider many of the criticisms of Quine's claims. See, e.g., P. Boghossian and C. Peacocke, eds (2000). More recently see C. Juhl and E. Loomis (2010); and G. Russell (2008).

31 Leiter (2007) 45-6.

32 Leiter (2007) 187.

33 Leiter (2007) 187-8.

34 Leiter (2007) 187. 
If various aspects of the legal model can support either side of any given dispute that comes before the Court, and the quality of these positions cannot be reliably and validly measured a priori, then the legal model hardly satisfies as an explanation of Supreme Court decisions. By being able to 'explain' everything, in the end it explains nothing. ${ }^{35}$

The next part of Leiter's illustration is key. For the Attitudinal Model to work, that is, for it to make sense and be successful as a predictiveexplanatory model of judicial decision-making, it must be possible to distinguish between the attitudes of the judges, which play a role in the best causal explanation of the decisions of judges, and the valid sources of law, which the Legal Model relies on in its explanation. Otherwise, it would not be possible to distinguish the Attitudinal Model from the Legal Model, and so compare these as competing predictive-explanatory theories. As Leiter explains, '. . . implicit in the Attitudinal Model is quite plainly a concept of law as exhausted by the authoritative texts (precedents, statutes, constitutions) which are the raw material of the competing Legal Model, and which exclude the ideological attitudes central to the Attitudinal Model.' ${ }^{36}$ The concept of law employed by the Attitudinal Model is, in the end, the 'exclusive' or 'hard' positivist concept of law best associated with Raz:

The concept of law, in turn, that vindicates [the Attitudinal Model] is none other than the Razian 'Hard Positivist' notion of a Rule of Recognition whose criteria of legality are exclusively ones of pedigree: a rule (or canon of interpretation) is part of the law by virtue of having a source in legislative enactments, prior court decisions or judicial practice, or constitutional provisions. That is the view of law required by the Legal Model, and it is the view required to vindicate the Attitudinal Model as providing the best explanation of judicial decision. Raz's Hard Positivism, in short, captures what law must be if the Attitudinal Model is true and explanatory. ${ }^{37}$

This is of course, as Leiter emphasizes, a very different way of defending hard or exclusive positivism from how Raz and others defend it. It may even turn out that an alternative predictive-explanatory theory might emerge, which does even better than the Attitudinal Model, and which might presume a still different concept of law. This is all possible, and in the spirit of Quine's insistence that all claims be tested against experience. But most importantly, Leiter's illustration is meant to show one way in which conceptual claims can be defended, albeit not in the traditional way.

\footnotetext{
35 Leiter (2007) 188. [author's notes omitted]

36 Leiter (2007) 189.

37 Leiter (2007) 189.
} 
This is to determine which conceptual claims about law are adopted or presumed in the most successful social scientific theories of law.

It is also important to note that the reliance of traditional conceptual analysis on appeal to intuitions has prompted other philosophers to turn towards more experimental methods in testing philosophical claims. The emerging field of 'experimental philosophy' begins with the observation that much philosophical reasoning makes use of appeal to intuitions, and pursues empirical research which investigates the universality of such intuitions.$^{38}$ Results often show that what philosophers have often taken to be reliable intuitions are rarely shared to anything approaching a level of universality, leading some researchers (often known as 'cognitive scientists') to explore more fully the connection between philosophical views and psychological belief-formation.

\section{THE LEGAL PLURALIST CHALLENGE}

Worries about the universality of intuitions about what is and what is not law go hand in hand with the third category of challenges to conceptual analysis. This type of challenge is found in the works of those who argue that the sheer diversity of types of law makes pursuit of a single concept of law, which identifies necessary or essential features of law, deeply wrongheaded. This group of critics, which is comprised for the most part of legal pluralists, criticizes analytical legal theorists for being unduly narrow and especially state-centric in the range of phenomena chosen from which to elucidate a concept of law. They argue that once the various manifestations and levels of law are acknowledged, it will be clear why there cannot be any single concept or essence of law.

For example, Brian Tamanaha argues that there is a truly wide range of phenomena legal theorists ought to investigate, which has important implications for general jurisprudence:

Law is whatever we attach the label law to, and we have attached it to a variety of multifaceted, multifunctional phenomena: natural law, international law, state law, religious law, and customary law on the general level, and an almost infinite variety on the specific level, from lex mercatoria to the state law of Massachusetts and the law of the Barotse, from the law of Nazi Germany to the Nuremberg Trials, to the Universal Declaration of Human Rights and the

38 For a representative collection, see the essays assembled in $\mathbf{J}$. Knobe and S. Nichols, eds (2008). But for a reaction to the perceived use of intuitions in philosophy, see H. Cappelen (2012). 
International Court of Justice. Despite the shared label 'law', these are diverse phenomena, not variations of a single phenomenon, and each one of these does many different things and/or is used to do many things ... No wonder, then, that the multitude of concepts of law circulating in the literature have failed to capture the essence of law - it has no essence. ${ }^{39}$

Tamanaha's strategy is to strip away all essential or necessary features of the concept of law (particularly those identified by H.L.A. Hart), which he believes have gone a long way towards creating a kind of 'analytical imperialism' 40 in legal theory whereby all new or different types of law are judged adversely against some purported standard of a central concept (typically a state-centred concept of law ${ }^{41}$ ).

Similarly, William Twining also argues that a narrow focus on state law overlooks much of what general jurisprudence ought to investigate, and that pursuit of an all-purpose concept of the essence or nature of law is misguided:

First, for the purposes of viewing law from a global perspective as part of a cosmopolitan discipline, a conception of law that is confined to state law (and maybe a few close analogies) leaves out far too much. There are many phenomena, which can be subsumed under the umbrella of non-state law, that are appropriate subject-matters of our discipline that would be excluded or distorted by such a narrow focus, such as various forms and traditions of religious or customary law. Second, to assume that law, or even state law, has a common nature or core involves reductionist and essentialist tendencies about which I am deeply sceptical. Rather, the picture that I wish to construct emphasizes the diversity, the complexity, and the fluidity of the phenomena with which we are or should be concerned. ${ }^{42}$

One way in which Twining believes that the different kinds of law can be distinguished is in terms of geographical levels, of which he identifies eight: global, international, regional, transnational, inter-communal, territorial state, sub-state, and non-state. ${ }^{43}$ However, as Twining also notes, the differences between these kinds of law are not just geographical differences; they include differences in structure, scope, and purpose as well. The cross-cutting variety of differences makes it pointless to search for a common core or concept.

It is possible to distinguish two main features of the pluralist views of Twining and Tamanaha. First, they maintain that a general jurisprudence,

\footnotetext{
39 B. Tamanaha (2001) 193.

40 Tamanaha (2001) 146.

41 For discussion of the dominant role state law has played in analytical jurisprudence, see K. Culver and M. Giudice (2010).

42 W. Twining (2009) 66.

43 Twining (2009) 69.
} 
by virtue of its very nature in being general, must take as its subject-matter law wherever and whenever it exists, and since state law is only one kind of law, it cannot be given any special theoretical priority. In this way, both Twining and Tamanaha are pluralists about the sources or types of law. Second, both Twining and Tamanaha maintain that the diversity of sources and types of law makes it impossible or at least unproductive to settle on an essence or nature of law: law's manifestations are simply too diverse. In this way, both Twining and Tamanaha are pluralists about the concept of law itself. ${ }^{44} \mathrm{We}$ can then say that the legal pluralist challenge has two parts to it: first, general jurisprudence must address a much wider range of phenomena than it has so far; and second, theorists ought to give up on developing single, all-purpose concepts of law.

Some might be tempted to point out that perhaps the legal pluralist challenge misses the mark since it essentially raises a different question from that raised by analytical jurisprudence. On the one hand, legal pluralism is a kind of socio-legal theory, concerned with exploration of the empirical variety of law around the world, and analytical jurisprudence, on the other hand, is simply concerned with a priori questions about the nature of self-knowledge about law. How could there be any meaningful conflict between these radically different projects? ${ }^{45}$ There are of course several popular criticisms of analytical jurisprudence (and especially legal positivism) which misunderstand its purpose. For example, regarding the analytical theory of legal positivism, it is often argued that it is mistaken because it offers no guidance to judges about how to decide cases; ${ }^{46}$ it entrenches conformist behaviour and unquestioning obedience, conduct which only greases the wheels of illegitimate regimes; ${ }^{47}$ and it has nothing to say about why particular legal systems develop in the particular ways that they do, recognizing different sources of law, different divisions of powers, and legal norms with different content. ${ }^{48}$ These criticisms of course raise important and interesting issues, but they ask different questions and so typically fail as criticisms of analytical jurisprudence. The first criticism asks for a prescriptive theory of adjudication, not a descriptive-explanatory theory of law. The second criticism is commonly held, but reveals radical misunderstanding of

44 There is, however, an important difference between the views of Tamanaha and Twining which I will discuss in the next chapter.

45 See K. Culver and M. Giudice (2013).

46 Dworkin (1986).

47 D. Dyzenhaus (2010).

48 H.P. Glenn (2005). 
legal positivism. And the third criticism asks for a causal, rather than conceptual theory of law.

The challenge raised by Tamanaha and Twining is significant precisely because it assesses the success of analytical jurisprudence on its own terms. Analytical jurisprudence purports to be in the business of identification and clarification of the conceptual commitments which come with understanding social life in terms of law wherever and whenever it exists. To recall Raz's view from the Introduction, analytical jurisprudence's aspirations are universal.

How well, then, has analytical jurisprudence succeeded on its own terms? According to Tamanaha and Twining, not too well at all. To add to their observations we can note that it is difficult to deny that analytical legal theorists, at least since John Austin, have focused their theories of law on explanation of law in the context of the modern state and its historical, imperial ancestors. For example, Austin explains the sample of data from which he thinks a general, universal jurisprudence can be constructed in the following way. He writes it is only the systems of two or three nations which deserve attention: - the writings of the Roman Jurists; the decisions of English Judges in modern times; [and] the provisions of French and Prussian Codes as to arrangement. ${ }^{39}$ His additional claim is key. As Austin says, 'From these, however, the rest may be presumed. ${ }^{50}$ Analytical legal theorists since Austin have developed richer and more sophisticated theories of law and legal system, but for the most part have not reached much beyond Austin's sample. For example, despite the aspiration for universality, in one place Raz settles on correct explanation of the nature of state law as an exclusive and sufficient criterion of adequacy for general theories of law. In the following passage he explains what he takes to be the 'assumption of the importance of municipal law':

It reflects our, or at least my, intuitive perception that municipal legal systems are sufficiently important and sufficiently different from most other normative systems to deserve being studied for their own sake. They are, or are part of, a form of social organization which is both important and different from most others and which therefore should be made an object of separate study. Obviously, in part the investigation of municipal systems is designed to compare and contrast them with other normative systems. Indeed it is to this part that the present essay is dedicated. In pursuing such investigations it may turn out that municipal systems are not unique, that all their essential features are shared by, say, international law or by church law. If this is indeed so, well and good. But it is not a requirement of adequacy of a legal theory that it should

\footnotetext{
$49 \quad$ J. Austin (2000) 373.

50 Austin (2000) 373.
} 
be so or indeed that it should not be so. It is, however, a criterion of adequacy that the theory will successfully illuminate the nature of municipal systems. ${ }^{51}$

Yet it is not even all municipal systems that count. As Raz adds: 'it is a criterion of adequacy of a legal theory that it is true of all the intuitively clear instances of municipal legal systems. ${ }^{52}$ Among the two hundred or so states that exist in the world today, which would count as the 'intuitively clear' instances? ${ }^{53}$ At the very least, the proliferation of different types of law, and especially the growing interactions and interdependencies of legal orders at various social levels (including local, national, transnational, regional, international and global) render Raz's commitment open to serious challenge on grounds of relevance and responsiveness to the social reality of law.

Together, the three objections present significant challenges to both the method and the goal of analytical jurisprudence as it is commonly understood, namely, as an exercise in conceptual analysis. If there is irresolvable disagreement about the concept of law which disrupts any presumption about its unity or coherence, or conceptual claims are always revisable in light of further experience or refutable if people do not share the necessary intuitions, or there are simply too many, different concepts of law around in the world, then how could conceptual analysis, which is analysis of some shared, unified concept in which the analyst's task is simply to make explicit what is already implicit in our knowledge and shared linguistic practice, form part of any sensible methodological approach to understanding law? And if there is such disagreement about the boundaries of the concept of law, or contingent and varied intuitions about its content, or simply several concepts of law, in what ways does it make sense to hold on to the idea that analytical jurisprudence might deliver necessary and essential features of law? Analytical jurisprudence seems doomed.

It is worth noting that the possibility of multiple concepts of law, each with diverse meanings and understandings, and drawing on different intuitions, undermines an otherwise illuminating recent defense of conceptual analysis in legal theory. In an article devoted to blunting the motivation and force of Quine's naturalized epistemology, Kenneth Himma sets out to defend 'traditional conceptual analysis' (TCA), in which conceptual

\footnotetext{
J. Raz (2009b) 105.

Raz (2009b) 104.

53 For discussion of whether some of the key elements of Raz's theory of legal system even explain accurately existing state legal systems which have a federal structure, such as Canada, see Culver and Giudice (2010) ch. 2.
} 
truths can be determined by appeal to intuitions shared by competent members of a linguistic and institutional community. Among other aims, Himma contends that intuitions occupy an ineliminable role not just in philosophical theorizing, but all theorizing. He also maintains that many of the most influential counter-examples to conceptual analysis, for example, that cats might not be animals since they might be martiancontrolled robots, or that the Pope is an unmarried adult male yet not a bachelor, are not really counter-examples at all to conceptual analysis as a way of doing philosophy, but only indications that our concepts of cat and bachelor are in need of further explanation or refinement. Himma uses these examples and others to show the difference between subjecting conceptual claims to empirical observation and subjecting regular empirical claims to observation or experience:

Falsifying a conceptual claim might involve an empirical element, but these elements are different in a theoretically important sense from the elements involved in falsifying other claims. A set of empirical observations falsifying the claim that some car averages 25 miles per gallon does not depend - at least not primarily - on a claim about how people use the relevant terms. Everyone agrees about what counts as the relevant car and about what counts as averaging 25 miles per gallon. A set of empirical observations falsifying the claim that all unmarried males are bachelors focuses on how people use 'bachelor'. While this is an empirical matter, it involves a different type of empirical issue than claims about how many miles per gallon a particular car averages. ${ }^{54}$

The link between conceptual claims and linguistic practices is therefore crucial to understanding the way in which conceptual claims are revisable and can change: so long as conceptual claims depend upon particular linguistic practices, and those linguistic practices can change, then so can conceptual claims change, even claims of conceptual necessity. What is important to realize, Himma argues, is that '... even if Quine is right in thinking all claims are subject to being revised in the face of experience, this does not imply there is not anything distinctive about conceptual claims or the methodology of conceptual analysis. ${ }^{55}$

How do these arguments bear on the concept of law? In Himma's view, the exercise of traditional conceptual analysis in legal theory is the same: we appeal to our intuitions, as competent members of some linguistic community, to analyse the concept of law, and make explicit its features and explore its metaphysical commitments. However, Himma does not pause to address the possibility, as Priel, Murphy, Leiter, Tamanaha and

54 K. Himma (2007) 30.
$55 \quad$ Himma (2007) 30. 
Twining might insist on, that there might be multiple, diverse linguistic communities employing different concepts of law, which might not share many or any common features at all. ${ }^{56}$ Consider the following representative passage:

People who analyse the concept of law, for example, take themselves to be explaining the nature of law. But, again, the nature of law, as we understand $i t$, is partly fixed by our shared practices, both institutional and linguistic, for using the relevant vocabulary. The fact that we use the term 'law' to refer to institutional normative systems, instead of to water, plays a role in determining the nature of the thing to which we refer by using 'law'. It is, after all, our concept of law that the theorist attempts to analyse; and the content of our concepts is at least partly fixed by our shared linguistic practices. ${ }^{57}$

There are two main presumptions that are made here, that are necessary for traditional conceptual analysis to achieve its goal with respect to the concept of law. The first is that our linguistic and institutional practices of using 'law' are relatively free from contradiction or inconsistencies, which may or may not be the case. Himma does not offer an argument one way or the other on this issue, yet traditional conceptual analysis seems to presume that there are no contradictions or inconsistencies. Otherwise traditional conceptual analysis would not have a proper object to explain or analyse, but only fragmented, contradictory, or inconsistent linguistic intuitions which would not reveal any shared concept of law. The second, related, and more important presumption in Himma's account is that there is some unified 'we', who hold such a single, coherent concept of law, indeed 'our' concept of law. But who the 'we' includes, and who it excludes, are not specified in Himma's account.$^{58}$ Without such specification it is not possible to apply traditional conceptual analysis to law, since it is not possible to identify the linguistic and institutional communities whose practices fix (even 'partly', in Himma's words, though it is not entirely clear what this qualification amounts to) the content of the concept of law. Indeed, it seems unclear just how traditional conceptual analysis could demonstrate, rather than simply presume, that there is some single, unified concept of law and some single, determinate and unified linguistic and institutional community. Everything would seem to

56 In discussing experimental philosophy's potential application to legal theory, Ian Farrell also explains that 'ethnographically relative results would contradict Hart's substantive claim that there is one general concept of law common to all "modern" legal cultures.' I. Farrell (2005-6) 1010. [author's notes omitted]

57 Himma (2007) 11-12. [original emphasis; author's notes omitted]

58 See also Coleman for similar 'we' and 'our' talk about the concept of law. J. Coleman (2001) ch. 12. 
hang, as Priel might repeat here, on what a theorist chooses to count as examples of law at a pre-theoretical stage (and we can only hope that the theorist chooses in such a way that the examples of law chosen do in fact fit together in a coherent or unified way worthy of analysis). In short, the presumption of unity, and its inherent circularity, seems to be a necessary condition for traditional conceptual analysis to get off the ground, but this makes traditional conceptual analysis vulnerable to the kinds of criticisms levelled against it by Priel, Murphy, and others.

One possible reply to this criticism would be to argue that there would be no way of knowing whether different communities, in using 'law', were indeed referring to the same or some similar object, without some overarching concept of law which would classify their different practices as law in the first place. I think this reply is on the right track, but notice that such a concept of law would likely need to be developed or constructed, since it might not exist in some particular, culturally-bound linguistic or institutional community. Its development would require resources, of the theoretical or philosophical kind, which transcend the particular commitments in particular linguistic and institutional communities, since analysis of some existing concept of law, held by some particular community, might be insufficient for discovering or establishing such an overarching concept of law. At the very least, such a concept of law cannot simply be presumed. As I will now begin to explain, and will take up more fully in the next chapter, it is this move from conceptual analysis to conceptual construction which is key to understanding the merits of the three challenges and their consequences for analytical jurisprudence as it is commonly conceived.

\section{BEYOND CONCEPTUAL ANALYSIS: A LOOK AHEAD}

With an account of the core challenges to analytical jurisprudence in hand, in the next chapter I turn to the task of assessing their net impact on analytical jurisprudence, and the role of conceptual analysis within it. As I noted in the Introduction, however, it is important to be clear that it will not be my aim to defend conceptual analysis, understood as the commitment to making explicit what is already implicit in some shared, single and unified concept of law that is presumed to already exist. As I shall explain further in the next and later chapters, I do not think that we ought to (nor do we need to) assume such a concept already exists, and is to be pursued by means of investigation of our intuitions or linguistic practices. As I shall also explain, I do not think that Hart, and even Raz, despite some 
appearances, were engaged primarily in conceptual analysis of the kind which restricts itself to elucidation of some single and unified concept of law that can be found in the beliefs and practices of participants in legal systems. Participants' beliefs about their own practices might be confused, distorted, or parochial, leaving it to philosophers to construct better conceptual explanations of their practices. In this sense, while conceptual analysis of the kind depicted and challenged in this chapter might be relegated among the aims of analytical jurisprudence and legal philosophy more generally, it does not follow that constructive conceptual explanation, in the sense of philosophical construction of new and improved concepts for use in explaining and understanding social reality, is also to be given up. The view I will defend and develop finds its inspiration in an account offered by Isaiah Berlin, who suggests that while identification of shared or popular concepts or categories and their essential properties is an important beginning, it is just that, only a beginning; conceptual analysis is not the final objective of philosophy. Berlin articulates the purpose of philosophy especially well. He writes, '[t]he task of philosophy, often a difficult and painful one, is to extricate and bring to light the ... categories and models [and concepts] in terms of which human beings think ... ${ }^{59} \mathrm{We}$ do this, according to Berlin, '. . . to reveal what is obscure or contradictory in [our categories, models and concepts], to discern the conflicts between them that prevent the construction of more adequate ways of organising and describing and explaining experience. ${ }^{60}$ For example, everyone might know and agree at some period in time that the environment just is the set of divisible and consumable natural resources ready for use and ownership by humans. Yet such an understanding of the environment, as we know now, may not (or at least may no longer) be terribly accurate or helpful in understanding or relating to the natural world. As Berlin notes, philosophical work sometimes requires the construction of new concepts, models or categories of thought which will better accomplish the task of explaining things to us and organizing our experiences. For Berlin, the motivation to engage in philosophy is clear:

It is certainly a reasonable hypothesis that one of the principal causes of confusion, misery, and fear is, whatever may be its psychological or social roots, blind adherence to outworn notions, pathological suspicion of any form of critical self-examination, frantic efforts to prevent any degree of rational analysis of what we live by and for. ${ }^{61}$

\footnotetext{
59 Berlin (1999) 10.

60 Berlin (1999) 10.

61 Berlin (1999) 11.
} 
To avoid misunderstanding, I should note that the constructive or revisionary aspect of conceptual work in philosophy is certainly not lost on contemporary advocates. Returning to Jackson, he notes:

There is nothing sacrosanct about folk theory. It has served us well but not so well that it would be irrational to make changes to it in the light of reflection on exactly what it involves, and in the light of one or another empirical discovery about us and our world. ${ }^{62}$

McGinn also emphasizes the 'corrective' and 'revisionary' dimension to philosophical analysis:

Analysis is often corrective and revisionary; clarification itself is a kind of revision - replacing unclear thoughts with clear ones. Compatibility analysis [between related concepts] can lead us to discover inconsistencies in our ordinary thought, with the result that important parts of our conceptual scheme are put under pressure and may have to be abandoned - such as free will or knowledge of the external world ... The conceptual analyst can be a revolutionary, too. ${ }^{63}$

I think Jackson and McGinn are right to observe the corrective or revisionary dimension to conceptual work in philosophy, but it might be more accurate not to lump such corrective or revisionary work under the label of conceptual analysis. Conceptual explanation, or perhaps even better, conceptual reconstruction might be a more apt characterization, to emphasize that conceptual theorists are not merely trying to retrieve or conserve the ordinary meaning involved in lay or folk concepts, but might be trying to change, deepen, or improve it, even if the labels - 'belief', 'knowledge', 'bachelor', 'law', etc. - remain the same. ${ }^{64}$

It is important to note that the issue here is not new, but was also acknowledged, if not resolved, in the works of Moore and Russell. Commenting on the distance we might find between pre-philosophical, ordinary views and the philosophical analyses that Moore and Russell produced, Scott Soames writes as follows about the "paradox of analysis': 65

\section{Jackson (1998) 44.}

63 McGinn (2012) 99-100.

64 For this reason, I find the following statement by McGinn misleading: 'Conceptual analysis is not necessarily conservative and uncritical' (McGinn, 2012, p. 100. If the concept under analysis (that is, its meaning or features) is to be changed or corrected, such change or correction signals that a theorist has moved from analysis to development or construction.

65 Soames (2003a) 164. 
The method pursued by Moore and Russell was one of analyzing the commonsense propositions one knows into their supposedly more basic constituents, thereby arriving at results that are less philosophically troublesome. But here is where the problem arises. If one comes up with an analysis that is strong enough to answer the initial philosophical questions that prompted one's inquiry, then it is likely to be complicated enough, and far enough removed from our ordinary understanding of the sentences being analyzed, that it becomes difficult to justify the claim that what one is doing is just revealing the content of the sentences as they were understood all along. On the other hand, if one's analysis sticks close to one's ordinary, pre-philosophical understanding, then it is likely not to produce anything substantial enough to resolve one's initial philosophical worries. In short, either one's analysis won't go beyond what one is analyzing, in which case one's philosophical worries won't go away; or one's analysis will show how one might resolve one's philosophical worries, but only by replacing that which one was analyzing with something new. ${ }^{66}$

The constructive task of philosophical concepts has also not gone unnoticed in legal theory. While he certainly does not share Hart's aims, I believe John Finnis nicely describes the character of Hart's work:

Late twentieth-century legal theory's paradigm text is called The Concept of Law. But despite the definite article ('the'), Hart's book takes it as obvious that there exist many concepts of law, and even of the law of sophisticated nation-states. The book does not for a moment try to establish that there exists in some communities, large or small, a concept of law which is entitled to be called 'the' concept of law. Instead it attends to the reality of law, both as a 'social phenomenon' and as a characteristic kind of 'reason for action', and - with notable if incomplete success - seeks by doing so to arrive at an 'improved understanding', a better concept, of law. Hart might more accurately, if less elegantly, have called his book $A$ New and Improved Concept of Law. ${ }^{, 67}$

Himma as well acknowledges the remedial dimension of conceptual work: '[i]f we find that a framework cannot help us make sense of the world or, worse, makes the world harder to understand, we might have a reason to modify or replace it. ${ }^{98}$ Jules Coleman, who also understands the traditional method of conceptual analysis to be engaged in analysis of our concept of law, nonetheless notes the corrective aspect of conceptual theories as well: 
Investigating common usage may allow a theorist to construct a "folk theory" of the concept of law, a more or less comprehensive (if incompletely articulated or rationalized) understanding of law's important features: rules, adjudicatory machinery, coercion, and the like. Conceptual analysis should be responsive to folk theory - sometimes by vindicating its claims, by showing the connection among the elements and their relationships to one another, and other times by requiring revisions in it. ${ }^{69}$

And yet, like Jackson and McGinn, both Himma and Coleman consider the revisionary work of conceptual theories as falling squarely within the task of conceptual analysis. This is just plain inaccurate and misleading. ${ }^{70}$ Worse, it directs attention away from the essential work that needs to be done in exploring and explaining just how we ought to go about revising

69 Coleman (2001) 200. Coleman also writes:

To be sure, we may demand as an adequacy condition of an analysis of the concept of law that it have resources adequate to explain the self-understandings of participants; but this does not mean that we must credit those selfunderstandings in the context of trying to understand what the practice is (2001) 188 (original emphasis).

More recently Coleman writes:

Normally, revision of a concept is justified when the ordinary concept is misleading and confusing or when it does not serve theoretical or practical purposes well. The revised concept is offered as otherwise providing insight or being particularly well-suited to certain explanatory or justificatory projects. Given that the ordinary concept is adequate for both practical engagement and the theoretical purposes of the social sciences, it is natural to ask what is special about the projects of jurisprudence that calls for revision in the concept of law (2011) 14.

70 In a very interesting and recent paper Andrei Marmor makes a similar observation:

Philosophers sometimes argue for conceptual claims that are explicitly acknowledged as revisionist; such concepts are not meant to reflect an agreement in judgments about the concept's application to all its standard cases. Therefore, counterexamples to the conceptual claim, based on prevailing linguistic intuitions or common usage, would not necessarily refute a revisionist concept. I am not denying here the possibility of such claims; it is certainly possible to define a concept that is revisionist in some sense. But then the concept would need to be supported by theoretical arguments about its usefulness or theoretical purpose, not by anything traditionally called conceptual analysis. An analysis of concepts is an analysis of the ways in which words function in our actual language games, which must be based on observation of linguistic practices and prevailing linguistic intuitions. Conceptual analysis cannot be revisionist. Concepts can be revisionist in various ways if they are properly defined and serve some useful theoretical purpose, but that is quite a different matter. (2013) 212. 
and constructing new conceptual explanations of law, and especially what triggers the need to revise and construct in the first place. As I shall argue in the next chapter, while the three challenges to analytical jurisprudence presented in this chapter effectively ignore its constructive conceptual work, their consideration nonetheless helps to reveal some of the important ways in which conceptual explanations of law can and ought to be constructed. It is to this task that I now turn. 